\title{
Equidad ética-jurídica de la ciencia para la emancipación del conocimiento y los saberes
}

\section{Ethical-legal equity of science for the emancipation of knowledge and knowledge}

DOI: http://dx.doi.org/10.17981/juridcuc.13.1.2017.2

Artículo de investigación. Fecha de recepción: 10/07/2017 Fecha de aceptación: 23/08/2017

José Manuel Perozo Piña ${ }^{1}$

Universidad Nacional Experimental Rafael María Baralt "UNERMB" (Venezuela) jmpp52@gmail.co

\author{
Oda González de González ${ }^{2}$ \\ Universidad Nacional Experimental Rafael María Baralt "UNERMB" (Venezuela) \\ odagonzalez@gmail.com
}

Para citar este artículo:

Perozo, J. y González, O. (2017). Equidad ética-jurídica de la ciencia para la emancipación del conocimiento y los saberes. JURÍDICAS CUC, vol. 13, no. 1, pp. 29-44. DOI: http://dx.doi.org/10.17981/ juridcuc.13.1.2017.2

\section{Resumen}

El estudio tiene el propósito de generar la discusión sobre la equidad ética y jurídica de la ciencia para la emancipación del conocimiento y los saberes a partir de la indagatoria reflexiva de los principios ético-jurídicos que fundamentan en la Constitución nacional de países como Chile, Perú, Ecuador, Colombia y Venezuela la significación de la ciencia construida desde los cimientos contextuales del conocimiento, los saberes y el sentido común originarios de América del Sur.

\footnotetext{
${ }^{1}$ Sociólogo con Doctorados en Ciencias gerenciales y en educación. Investigador-coordinador de la línea de investigación Ethos y culturas en la organización. Docente jubilado UNERMB.

${ }^{2}$ Socióloga con Doctorado en Ciencias gerenciales. Participante de la línea de investigación Ethos y culturas en la organización. Docente titular jubilada UNERMB. Adscrita al Centro de estudios sociales, económicos y políticos (CEISEP) de UNERMB.
}

- The author; licensee Universidad de la Costa - CUC. 
La indagatoria reflexiva está orientada desde la sociología jurídica para abordar la contrastación y la sistematización de los artículos constitucionales que visibilizan la emancipación del conocimiento integrado a los saberes originarios en los citados países. El artículo es un avance del proyecto de investigación titulado "Contextualización del conocimiento emancipador desde lo local", que los autores adelantan en la línea de investigación Ethos y culturas en la organización (UNERMB-CDHCT). Se llega a la consideración final de que es evidente la equidad en los principios ético-jurídicos en las Constituciones nacionales de Chile, Perú, Ecuador, Colombia y Venezuela para integrar saberes y el sentido común al conocimiento, desde una ciencia construida por y para América del Sur.

\section{Palabras claves}

Saberes, identidad, emancipación, significación y constitución.

\section{Abstract}

The purpose of the study is to generate a discussion on the Ethical-Legal Equity of Science for the Emancipation of Knowledge and Knowledge, based on the reflective investigation of the ethical-legal principles that underpin the National Constitution of countries such as Chile, Peru, Ecuador, Colombia and Venezuela the significance of science built from the contextual foundations of knowledge, knowledge and common sense originating in South America. Reflective inquiry is oriented from juridical sociology, to approach from the contrasting and systematization of the constitutional articles, that make visible the emancipation of the integrated knowledge to the original knowledge in the mentioned countries. The article is an advance of the research project titled "Contextualization of emancipatory knowledge, from the local", that the authors advance in the Line of Research Ethos and cultures in the Organization (UNERMBCDHCT). The final consideration is that equity in ethical and juridical principles in the National Constitutions of Chile, Peru, Ecuador, Colombia and Venezuela to integrate knowledge and common-sense knowledge, from a science built by and for South America.

\section{Keywords}

Knowledge, identity, emancipation, meaning and constitution 


\section{INTRODUCCIÓN}

El espacio de desarrollo del conocimiento y los saberes en el marco epistemológico de la concepción del ser como sujeto cognoscente, viene sufriendo una ruptura en la relación entre la intersubjetividad y el marco ético-jurídico que fundamenta la legitimidad de las representaciones estructurales del cuerpo de teorías y métodos científicos. En el caso de América del Sur, como lo plantea Sousa (2010) en su estudio de América del Sur en el marco de la globalización, es evidente la debilidad de las teorías sociales universales, las cuales se pueden reconstruir desde la óptica emancipadora que surge de las comunidades y los intelectuales que generan teorías profundamente consustanciadas con los saberes definidos como ancestrales y el sentido común. Surge entonces la necesidad de avanzar en la ruptura para que desde cada espacio académico se haga visible la significación que, en la construcción de conocimiento, tienen los saberes y el sentido común originario de América del Sur.

El artículo "Equidad ética-jurídica de Ciencia para la emancipación del conocimiento y los saberes", es un avance de la investigación en curso Contextualización del conocimiento emancipador desde lo local, que desarrolla el equipo de investigadores adscritos a la línea de investigación Ethos y Culturas en la Organización (CDHCT-UNERMB). En este sentido, desde la visión de la sociología jurídica, se indagó en la Constitución nacional vigente de Chile, Perú, Ecuador, Colombia y Venezuela para contrastar y sistematizar en el sistema ético-jurídico constitucional la posibilidad de hacer visible la significación que asume en América del Sur la integración de saberes y sentido común en la construcción del conocimiento para generar ciencia.

El fundamento metódico lo constituye la revisión documental de las Constituciones de Chile, Colombia, Perú, Ecuador y Venezuela, con el propósito de comprender los elementos que dan fuerza en el sistema jurídico a los contenidos extra-científicos de significación espiritual y del sentido común como validador de una razón objetivada en la ética para producir ciencia, integrada al contexto de conocimientos y saberes que fundamentan la identidad de las naciones de América del Sur. 
Fundamentación epistémica para la contextualización de la equidad ética-jurídica de la Ciencia

Prodigio de la creación humana, la ciencia es fuente de profundas divergencias, pero, así mismo, no hay duda de su influjo para dominar la racionalidad a través de principios y leyes universales sobre la sociedad, la naturaleza y el cosmos; fundamentos que le asigna a la ciencia la cualidad de ser ética en sí misma. La ciencia es la amalgama del saber-hacer integrado al conocimiento sistemático desde el juicio del sentido común y/o de afirmaciones verificadas, que en ambos casos sentencian la declaración afirmativa o negadora de un juicio científico.

Con el insigne filósofo argentino Bunge (1981), se encuentra que: "La ciencia es valiosa como herramienta para dominar la naturaleza y remodelar la sociedad; (...) en el enriquecimiento, la disciplina y la liberación de nuestra mente" (p. 36). Esta acepción de Bunge es comprensible en tanto que, como creación humana, la ciencia es un sistema de relaciones sociales cuyo propósito es promover esquemas conceptuales dominantes en periodos históricos definidos por la misma racionalidad ética que imponen. No obstante, la racionalidad ética que impone la ciencia requiere del ordenamiento extra-científico de la racionalidad del Estado y de la sociedad para constituirse en una ciencia independiente, aun de la misma razón que la crea.

Es innegable cómo el devenir de la historia de la humanidad pasó del misticismo del orden natural a la racionalidad de la lógica del dominio del hombre sobre su ambiente. Dominar el fuego y la comprensión del uso prensil de las manos significó la ruptura del dominio de la naturaleza sobre el hombre; salto prodigioso para alcanzar el dominio de la máquina, que se constituyó al interior de la sociedad en la separación del intelecto del trabajo físico.

Hoy la sociedad del conocimiento hace intangible la dominación de la ciencia sobre la racionalidad contextual del conocimiento que la crea. El saber, el sentido común que fundamenta los primeros años de vida, se esfuma de la conciencia con el advenimiento de la educación formal y la carrera profesional. 
América del Sur parece estar resignada al dominio de la ciencia difundida a través de la tecnología digital, donde el conocimiento se valora a partir del juicio ético proporcionado desde los centros internacionales de información, los cuales imponen la visión global que superará las visiones del conocimiento, los saberes o el sentido común construidos socialmente desde lo local.

Acepciones de la sociología jurídica para la construcción de la equidad ética-jurídica de la ciencia

Desde la perspectiva de la sociología jurídica, sería cómodo iniciar esta disertación sobre la cuestión de lo ético y lo jurídico a partir de la propuesta de autores como Weber (1964), pero, en todo caso, la sensación de ir hacia una filosofía del Derecho encamina la esencia especulativa de los autores hacia el carácter significativo de lo justo en la sociedad. Lo justo, apegado a la norma de derecho, tendrá una connotación desde la Sociología como aquello ligado a la experiencia reflexiva, producido desde interpretaciones presentes en las estructuras mentales para juzgar el intelecto y ajustado al sistema jurídico vigente en un determinado contexto.

En Kelsen (1988) se encuentra la distinción del ámbito individual y social de la ciencia, bien sea el caso de la ciencia jurídica; este hecho es importante porque permite hacer la referencia al científico como aquel individuo que posee una moral de sí mismo y de su existencia. Una existencia individual que está referida al ámbito de la moral social y que le permite reconocerse como sujeto social a través del proceso de socialización.

La conformación de una moral para asumir el rol de científico no solo se debe adaptar a los preceptos normativos de la comunidad científica, sobre ellos está la norma moral de la sociedad en general.

La comprensión de la ciencia jurídica como sistema perceptible la condiciona a las regulaciones sociales, que se derivan del comportamiento de variables económicas, sociales, culturales, políticas e ideológicas. Esta reflexión, fundamentada en auto- 
res como Feyman (2000), ubica a la presente indagatoria en la posibilidad de concebir la ciencia como un hecho social, cuyo interés debe corresponderse con los intereses de la sociedad en general. Quizás no se encuentren palabras tan ilustrativas del tema como las del referido autor:

Estamos solo al principio de la raza humana; del desarrollo de la mente humana, de la vida inteligente: tenemos años y años por delante. Tenemos la responsabilidad de no dar hoy todas las respuestas, de no dirigir a todo el mundo en una dirección y decir -Esta es la solución de todo-. Porque entonces estaremos encadenados a los límites de nuestra imaginación actual. Solo seremos capaces de hacer aquellas cosas que hoy pensamos que son las cosas que hay que hacer. Mientras que, si dejamos siempre algún resquicio a la duda, algún lugar para la discusión y procedemos de una forma análoga a las ciencias, entonces esta dificultad no aparecerá. Por consiguiente, creo que, aunque hoy no sea el caso, puede llegar un día, me gustaría confiar en ello, en que seamos completamente conscientes de que el poder del gobierno debería ser limitado; que los gobiernos no deberían tener el poder de decidir la validez de las teorías científicas; que es ridículo que traten de hacerlo; que no van a determinar las diversas descripciones de la historia o de la teoría de la economía o de la filosofía. (2000, p. 95)

El deber-ser instituido, lo que por regla general se da como deber para el ser, bien puede quedar olvidado en el del acervo cognitivo cuando no es ejercido en el devenir de la historia. Es así como en América del Sur no es solo necesario, como se verá más adelante (que el sistema ético-jurídico formule principios dirigidos a orientar el desarrollo de la ciencia), sino que es necesario el concurso de quienes en las instituciones, empresas y organizaciones sociales dediquen su esfuerzo a integrar la ciencia a los saberes que fundamentan la realidad de contextos locales.

Es en este punto donde el propósito general de encontrar la equidad ética y jurídica de la ciencia cobra sentido el conocimiento y los saberes como reafirmación de hitos que marcan la conformación de hechos, situaciones y personas identitarias de la conformación del contexto nacional, constituido en principio por su presencia histórica. 
Fundamentación sociohistórica de la razón ético-jurídica de la ciencia en América del Sur

La complejidad figurativa del imaginario de América del Sur fundamenta la contextualización de aportaciones de carácter universal de insignes mujeres y hombres que dejaron constancia de su valor intelectual, entre los cuales se pueden citar: Don Francisco de Miranda, venezolano que con el rango de coronel de los ejércitos rusos dejó su huella en la Revolución Francesa y en la Independencia de los Estados Unidos; San Martín y Bolívar, libertadores de Argentina, Chile, Perú, Colombia, Ecuador, Bolivia y Venezuela; Manuela Sáenz (Venezuela); Micaela Bastidas (Perú); Manuela Beltrán (Colombia); María Remedios del Valle (Argentina); y las chilenas Lucila Godoy Alcayaga (Gabriela Mistral, Premio Nobel de Literatura en 1945) y Violeta Parra. Todos ellos, ilustres visionarios de la fuerza creativa del saber para reconfigurar la realidad en favor de la emancipación del contexto local sobre la dominación de la globalización social.

Pero el comportamiento práctico-moral no es solo un acto individual, tal como lo refiere Sánchez (1984), éste sucede con base en la reflexión valorativa que se experimenta socialmente para accionar comportamientos entre sujetos que se asocian para revertir situaciones que los afectan como colectivo. Acciones de individuos-colectivos que resultan en la afectación de la ética por la necesidad que surge de adecuar la conducta a los cambios que se suceden. Visión de la ética que cobra vigencia ante la necesidad de explicar la incontrolable influencia, más allá de la valoración legislativa, que cobra en América del Sur la búsqueda de límites a la racionalidad técnica del cientificismo dominante de las ciencias globales para renovar la emancipación del conocimiento forjado desde contextos concretos de notable influencia en el devenir histórico. En esta perspectiva, es visible la carga ética que surge de sujetos históricos, comprometidos en reconstruir rupturas epistémicas emancipadas de creencias y valoraciones desde y para la dominación universal cientificista. 


\section{Pensamiento ético-jurídico para la emancipación de la ciencia}

El pensamiento ético es la inquietante búsqueda de la adecuada explicación de la realidad, juzgada en equidad para todos los que conforman la sociedad en un espacio y tiempo concreto. Esta necesidad de comprensión del hombre en relación con sus otros y el hábitat que ocupa, viene requiriendo procesos de trasformación de las formas de conocer, de asociarse para pensarse desde una ética construida desde y para lo social.

La ciencia y la generación de conocimiento están despertando intensos procesos de reflexión en América, y deseamos sumar este esfuerzo a esos escenarios con el firme propósito de promover la toma de conciencia sobre temas como la ética de la ciencia, el alcance y ámbito del sistema jurídico que la regula, la objetividad del conocimiento, el fetiche de la eficacia tecnológica y el reduccionismo del conocimiento al exclusivo campo académico universitario y comunidades científicas. Al respecto, Sousa (2010) hace referencia a la abolición de paradigmas universalmente dominantes para indagar sobre paradigmas emergentes caracterizados por la superación de los límites impuestos desde el positivismo científico, avanzando de esa forma a un conocimiento integral del contexto de América del Sur.

Esta realidad ha inquietado históricamente a quienes se ocupan del tema de los modelos del pensar ético sobre la realidad exterior al ser y sobre sus capacidades para comprenderse así mismo en los modelos creados. En este sentido, Ricoeur (2006) señala que la humanidad "(...) ha cambiado de actitud en relación al mundo; no se contenta más con contemplar, mirar, admirar, él busca dominar y poseer" (p.28). En esta intención de presentar un pensamiento válido, la ética termina situándose en contraposición a la realidad de la cual se ocupa. Está allí, en los preámbulos constitucionales, para interiorizar un tipo de integración a la normativa jurídica que posibilita la coexistencia, bajo cierta armonía, entre diversos valores sociales.

La sociedad se va organizando alrededor de la valoración ética. La actitud individual se acomoda entre la gama de valores para alcanzar sus aspiraciones particulares. Quienes hacen ciencia no están libres de eximirse de sus aspiraciones individuales. El objetivo de la neutralidad de la ciencia se guía entre la diversidad de 
valores, por lo jurídicamente válido y la gama de intereses contradictorios de las relaciones sociales.

El pensamiento ético ha formalizado lo válido jurídicamente para que desde la ciencia se abra la posibilidad de interpelar la realidad, sobre la particular idea de lo justo, lo moralmente ético dentro de la razón del Estado.

\section{Razón ética y jurídica de las representaciones de la Ciencia}

La ciencia como constructo social surge en el vorstellung (Lakatos, 1981), esto es, cuando se muestra como expresión de juicio explicativo, ordenador de la estructura conceptual de representaciones de la visión de uno o más individuos. La preponderancia de juicios explicativos toma vigencia en tanto representa la legitimidad de leyes explicativas de la sociedad.

Las parcelas de la inteligencia legitiman y organizan campos de indagaciones diversas y en ocasiones contradictorias entre sí. Solo ascenderán a legitimarse aquellas que el conjunto de la comunidad científica llega a constituir como representación de las formas del pensar en el contexto del orden jurídico constitucional.

Estos planteamientos, que se soportan en la investigación de Báez (2008) acerca de la censura que legitima las representaciones dominantes de la ciencia, señalan que se ha llegado incluso al “(..) saqueo de la memoria colectiva, impuesto por los regímenes de fuerza al activar mecanismos de represión, censura y destrucción" (p. 151). Este referente, lo fundamenta el citado autor para el caso venezolano, donde, entre 1909 y 1935, la elite en el poder “(...) se hizo rodear de un grupo de intelectuales para imponer un orden legislativo e intelectual que censuró periódicos e imprentas, acalló a decenas de autores" (p.153), imponiendo un orden jurídico que legitimó las representaciones de la ciencia soportada por el acervo sociocultural y científico global. Referente teórico que da cuenta del contexto ético-jurídico hegemónico de representaciones de la ciencia, en tanto configuran la referencia dogmática de la inteligencia latinoamericana. En este sentido, cobra vigencia expresar que, desde las instituciones educativas, científicas y tecnológicas latinoamericanas, se deben construir las explicaciones radicalmente diferenciadas del cientificismo dominado por la elite de la inteligencia universal. 
Surge la necesaria visibilidad de la inteligencia latinoamericana, para que materialice en acciones la significación expositiva de la equidad ética y jurídica del conocimiento, los saberes y el sentido común, construidos desde contextos locales. Genialidades como Fals Borda, Freire, Ribeiro, Cortázar, Borges, Vargas Vila, Vargas Llosa, García Márquez, Convit y Fernández Morán, son insignes representantes de nuestra inteligencia latinoamericana; sin embargo, allí están, en la absoluta invisibilidad maestros, por citar un ejemplo, que vienen transformando las formas de aprender en escuelas alejadas del campus cientificista de la inteligencia académica que fungen de cinturón protector del centro firme de la ciencia.

\section{Metódica para la construcción del avance reflexivo}

El carácter de revisión documental soporta el conjunto de reflexiones organizadas en este avance de la investigación Contextualización del conocimiento emancipador desde lo local, investigación iniciada en octubre de 2016, que tiene como propósito principal hacer visible desde el sistema explicativo metaempírico, la unidad coherente e independiente de procesos socio históricos, culturales, económicos y políticos, constituidos por acciones de personas e instituciones, que, por su carácter científico como extra científico, se constituyen en cimiento de realidades objetivamente constituidas, tanto del saber surgido del sentido común, como de la constructiva conceptualización del conocimiento extracientífico.

En la siguiente sección se presenta un avance reflexivo, que será enriquecido desde la indagatoria documental de algunos textos constitucionales de países de América del Sur para entender cómo se concibe la comprensión de una ética jurídica de la ciencia vinculada e integrada a las formas ancestrales de saberes y sentido común que dieron identidad a las naciones.

Avance reflexivo: El camino paradigmático de la equidad éticojurídica de la ciencia

El punto de ruptura orientador de estas reflexiones está cimentado en concebir el Derecho como factor de estabilidad del Estado para sustentar el crecimiento interno, en el cual uno de los factores a 
considerar es la equidad ética-jurídica de la ciencia. Se entiende el Derecho como factor de estabilidad del Estado. Esta segunda afirmación se sustenta en la concepción del Estado democrático con posición firme frente a la interdependencia económica y cultural con la comunidad internacional. Hoy, en América del Sur, es prioritario consolidar la relación entre democracia y el Estado de derecho para consolidar la armonía social.

En el proceso metódico se desarrolló la revisión documental de la Constitución nacional de Chile, Colombia, Venezuela, Ecuador y Perú con la intención de documentar esta relación intrínseca entre la ciencia, la educación, el conocimiento, los saberes y el sentido común bajo la observación del ordenamiento ético-jurídico que establece la Constitución nacional como instrumento fundamental del Estado de derecho para todos los ciudadanos.

Es justo iniciar con la Constitución Política de Perú (República de Perú, Congreso Constituyente, 1993), la cual deja constancia plena que la "potestad de administrar justicia emana del pueblo peruano" (art. 138), "heredero de las generaciones precedentes que dieron todo por la libertad de su patria" (preámbulo); "ciudadanos que disfrutan entre otras libertades de expresión del pensamiento, creación intelectual, artística, técnica y científica para actuar en plena libertad de conciencia para ejercer la propiedad de dichas creaciones y sus productos" (art. 2).

Concebidos como ciudadanos inspirados en la ética heredada de los forjadores de la patria, tanto la Constitución peruana como la Constitución de la República Bolivariana de Venezuela (República Bolivariana de Venezuela, Asamblea Constituyente, 1999) en sus preámbulos invocan el pasado originario de "precursores y forjadores de la patria libre y soberana" (preámbulo). Esta afirmación del espíritu fundacional, se sustancia en el artículo 99 que le asigna al Estado venezolano la protección del patrimonio cultural que es "inalienable, imprescriptible e inembargable" como ordenamiento que se compromete a la "protección de la propiedad intelectual sobre obras científicas, literarias, artísticas, invenciones, innovaciones" (art. 98).

La Constitución de la República Bolivariana de Venezuela reconoce el "interés público a la ciencia, la tecnología, el conocimiento, la innovación y sus aplicaciones" (art. 110) para lograr fomentar el desarrollo económico social y político del país. 
Estos aportes son importantes para apuntalar el fundamento de la fortaleza científica y tecnológica propia, con vinculación directa de sus intelectuales e inventores al desarrollo nacional, lo que toma cuerpo ético-jurídico en el texto constitucional de Venezuela.

Ajustado al protocolo fijado de revisión documental, el hilo conductor está presente en la Constitución Política de la República de Chile (República de Chile, Consejo de Estado, 2005), la cual asegura en su artículo 19 que todas las personas están en la libertad de "crear y difundir las artes, así como el derecho del autor sobre sus creaciones intelectuales y artísticas de cualquier especie, por el tiempo que señale la ley y que no será inferior al de la vida del titular." Este aspecto jurídico es importante pues ubica al intelectual chileno en la libertad de participar con patentes nacionales en los tecnológicos que beneficien el desarrollo industrial, comercial y social del país.

La constitución otorga significaciones lógicas a circunstancias condicionantes, deberes y facultades que tipifican la libertad de crear ciencia en el contexto del país sin mayores restricciones que las impuestas por las leyes que regulan la materia. En este sentido, la Constitución de la República del Ecuador (República de Ecuador, Asamblea Nacional Constituyente, 2008) en su artículo 25 establece que "Las personas tienen derecho a gozar de los beneficios y aplicaciones del progreso científico y de los saberes ancestrales".

Así, los saberes ancestrales están presentes en el preámbulo de la Constitución de Ecuador, cuya significación expresa lo siguiente: "Reconociendo nuestras raíces milenarias, forjadas por mujeres y hombres de distintos pueblos" y "apelando a la sabiduría de todas las culturas que nos enriquecen como sociedad", con el firme propósito de luchar "como herederos de las luchas sociales de liberación frente a todas las formas de dominación y colonialismo", los cuales son principios éticos y jurídicos para generar, con base en el contexto social, la conjunción de conocimientos y saberes y la integración a la ciencia surgida en el contexto nacional. Más adelante, en la sección VIII, en el artículo 385, la Constitución ecuatoriana establece que el sistema nacional de ciencia, tecnología, innovación y saberes ancestrales tendrá como finalidad: "generar, adaptar y difundir conocimientos científicos y tecnológicos; recuperar, fortalecer y potenciar los saberes ancestrales y desarrollar 
tecnologías e innovaciones que impulsen la producción nacional, eleven la eficiencia y productividad, mejoren la calidad de vida y contribuyan a la realización del buen vivir".

El sistema jurídico en los países de América del Sur, de al menos los vistos hasta ahora, vinculan la ciencia, la tecnología y las innovaciones al bienestar nacional. De allí que, en apreciación de Fals (2009), la significación ética-jurídica de la ciencia y sus métodos vale en tanto es vista en la actitud de "responsabilidad y honradez que deben distinguir a todo científico" (p. 233). Este genial escritor colombiano apunta a la comprensión de que la norma jurídica da significación ética a la tipificación de la conducta deseable de sujetos que tienen libre acceso "al conocimiento, a la ciencia, a la técnica y a los demás bienes y valores de la cultura", tal como lo establece el artículo 67 de la Constitución Política de Colombia (República de Colombia, Corte Costitucional, 2015). La citada constitución es taxativa en este sentido:

La búsqueda del conocimiento y la expresión artística son libres. Los planes de desarrollo económico y social incluirán el fomento a las ciencias y, en general, a la cultura. El Estado creará incentivos para personas e instituciones que desarrollen y fomenten la ciencia y la tecnología y las demás manifestaciones culturales, y ofrecerá estímulos especiales a personas e instituciones que ejerzan estas actividades (art. 71).

El fomento e innovación de la ciencia y la tecnología vinculante al desarrollo social y económico es profundamente significativa en los ordenamientos jurídicos revisados en este artículo. La Constitución de Ecuador (2008) avanza en este aspecto al establecer la equidad y la inclusión de la ciencia y la tecnología con otros sectores, que se articulan al Plan de Desarrollo Social bajo los principios de universalidad, igualdad, equidad, progresividad, interculturalidad, solidaridad y no discriminación (art. 340).

Es importante resaltar que, derivado de la contrastación entre las Constituciones de los países citados en este avance de investigación, prevalece el encuentro de criterios de valoraciones significativas para visibilizar la equidad ética-jurídica y generar la adaptación y la difusión del conocimiento científico y de tecnologías integradas al saber y el sentido común. En la tabla siguiente se resaltan los principios constitucionales donde se hacen visi- 
ble la equidad ético-jurídica de la ciencia para fundamentar la emancipación del conocimiento y los saberes en América del Sur.

Tabla 1

Principios de equidad ético-jurídica

\begin{tabular}{|c|c|}
\hline Hallazgo constitucional & Aporte ético-jurídico emancipador \\
\hline $\begin{array}{l}\text { La potestad de administrar justi- } \\
\text { cia emana del pueblo. } \\
\text { Expresión del pensamiento, crea- } \\
\text { ción intelectual, artística, técnica } \\
\text { y científicas para actuar en plena } \\
\text { libertad de conciencia para ejercer } \\
\text { la propiedad intelectual. } \\
\text { Recuperar, fortalecer y potenciar } \\
\text { los saberes ancestrales } \\
\text { Derecho a los beneficios y aplica- } \\
\text { ciones del progreso científico y de } \\
\text { los saberes ancestrales. } \\
\text { Generar, adaptar y difundir cono- } \\
\text { cimientos científicos y tecnológi- } \\
\text { cos al saber y sentido común. } \\
\text { Apelar a la sabiduría de todas las } \\
\text { culturas que enriquecen la socie- } \\
\text { dad. } \\
\text { Firme propósito de luchar y prote- } \\
\text { ger la propiedad intelectual sobre } \\
\text { obras científicas, literarias, artís- } \\
\text { ticas, invenciones e innovaciones. }\end{array}$ & $\begin{array}{l}\text { El principio constitucional del poder } \\
\text { originario del pueblo para administrar } \\
\text { la justicia social, la cual entre otros } \\
\text { fundamentos tiene la plena libertad de } \\
\text { conciencia para la expresión del pen- } \\
\text { samiento, la creación intelectual, ar- } \\
\text { tística, técnica y científica, aplicada al } \\
\text { proceso del conocimiento científico y los } \\
\text { saberes ancestrales. } \\
\text { Se observa la referencia a la integra- } \\
\text { ción del conocimiento científico y los } \\
\text { saberes ancestrales con el señalamien- } \\
\text { to expreso hacia el individuo-colectivo } \\
\text { en el cual recae la potestad de ejercer la } \\
\text { justicia social. } \\
\text { En este sentido es importante subra- } \\
\text { yar los postulados de Maturana (1997) } \\
\text { acerca del referente social de la cien- } \\
\text { cia, para impulsar desde allí, el orden } \\
\text { normativo que legitima realidades di- } \\
\text { ferenciadoras para recrear el accionar } \\
\text { ético integrador del conocimiento y los } \\
\text { saberes como dominios emancipados de } \\
\text { criterios de validación científica de ca- } \\
\text { rácter global. }\end{array}$ \\
\hline
\end{tabular}

Fuente: Cuadro elaborado por los autores con información tomada de las Constituciones de Perú, Chile, Ecuador, Colombia y Venezuela.

La evidente contrastación de encuentros en los principios constitucionales para incorporar en el sistema jurídico evidencias de integración para generar, adaptar y difundir el conocimiento científico, la tecnología y el saber, abren expectativas favorables para sistematizar acciones activadoras de la conciencia de sujetos históricos que lideren la emancipación del conocimiento y el saber. 


\section{CONCLUSIONES}

La necesidad de reconstruir un cuerpo teórico-metódico que fundamente el propósito de indagación reflexiva para dar significación ética y jurídica al valor que criterios no científicos (sentido común, saberes, creencias) tienen para fundamentar la validación científica de la realidad es el espíritu que orientó esta disertación acerca de la equidad ético-jurídica de la ciencia.

Términos como saberes ancestrales no deben ser tomados como un atajo subjetivo para una pretendida validación cualitativa de la ciencia, nada más alejado de la realidad, deben ser tomados como referentes de la emancipación necesaria de la razón divergente y crítica de praxis sociales involucradas al saber disponible tras la socialización; razón que habilita a los investigadores para comprender conscientemente las significaciones del inconsciente para visibilizar en su percepción la objetivación de lo que pertenece al ser y lo que pertenece a la realidad cuestionable.

En el sistema jurídico de los países observados hay suficientes elementos de significación ética que permiten fundamentar en la producción científica la fuerza de la unidad de la racionalidad de saberes, valores espirituales y conocimiento científico, tecnológico e innovación.

Hacer consciente en la comunidad científica planteamientos como los que están presentes en este artículo es significativo para revalidar a brillantes investigadores surgidos a fuerza de la práctica equitativa, justa y ética de visibilizar aprendizajes propios y colectivos configurados por el sentido común y los saberes que le aportan significaciones trascendentales para reconocerse a sí mismo como aprendiz innovador de su propio conocimiento, fuerza impulsora de la ciencia en América del Sur.

\section{REFERENCIAS}

Báez, F. (2008). El saqueo cultural de América Latina. De la conquista a la globalización. Serie Debates. Venezuela: Melvin. Bunge, M. (1981). La ciencia, su método y filosofía. Buenos Aires, Argentina: Siglo XX. 
Fals, O. (2009). Una sociología sentipensante para América Latina. Consejo Latinoamericano de Ciencias Sociales - CLACSO. Colombia: Siglo del hombre.

Feyman, R. (2000). El placer de descubrir. España: Crítica.

Kelsen, H. (1988). Teoría pura del Derecho. México: Porrúa.

Lakatos, I. (1981). Matemática, ciencia y epistemología. España: Alianza.

Maturana, R. (1997). La realidad: ¿Objetiva o construida? (II) Fundamentos biológicos del conocimiento. México: Anthropos.

República de Colombia. Corte Constitucional. (2015). Constitución Politica de Colombia. Bogotá, D.C.: Imprenta Nacional. Recuperado de: http://www.corteconstitucional.gov.co/inicio/Constitucion\%20politica\%20de\%20Colombia\%20-\%202015.pdf

República de Chile. Consejo de Estado. (1980). Constitución Politica de la República de Chile. Recuperado de: pdba.georgetown. edu/Parties/Chile/Leyes/constitucion.pdf

República del Ecuador. Asamblea Nacional Constituyente. (2008). Constitución de la República del Ecuador. Registro Oficial No. 449. Recuperado de: http://aceproject.org/ero-en/regions/ americas/EC/constitucion/ecuador-constitucion-politica-de-larepublica-del/view

República de Perú. Congreso Constituyente Democrático. (1993). Constitución Política de Perú. Recuperado en: www.portal.jne. gob.pe7/./CONSTITUCION\%2POLITICA\%20DEL\%PERU

República Bolivariana de Venezuela. Asamblea Constituyente. (1999). Constitución de la República Bolivariana de Venezuela. Gaceta Oficial No. 5.980. Recuperado de: http://www.minci.gob.ve/wp-content/uploads/2011/04/CONSTITUCION.pdf

Ricoeur, P. (2006). La vida: un relato en busca de narrador. Argentina: UCA-Prometeo.

Sánchez, A. (1984). Ética. España: Crítica.

Sousa, B. (2010). Descolonizar el saber, reinventar el poder. Uruguay: Trilce.

Weber, M. (1964). Economía y sociedad. México: FCE. 